\title{
Endotoxins of Enteric Pathogens Are Chemotactic Factors for Human Neutrophils
}

\author{
Laila N. Islam*, A.H.M. Nurun Nabi, K. Mokim Ahmed and Novera Sultana \\ Department of Biochemistry and Molecular Biology, University of Dhaka, Dhaka-1000, Bangladesh.
}

Received 15 July 2002, Accepted 5 August 2002

\begin{abstract}
Early activation of human peripheral blood polymorphonuclear neutrophils is characterized by their morphological changes from spherical to polarized shapes. The endotoxins from enteric pathogens $(S$. dysenteriae type $1, V$. cholerae Inaba 569B, S. typhimurium, and $K$. pneumoniae) were assessed by their ability to induce morphological polarization of the neutrophils as measures of early activation. Phagocytic activity, adhesion, chemokinetic locomotion, and nitroblue tetrazolium (NBT) dyereduction ability measured the later activation of the cells. Neutrophils showed distinct morphological polarization in suspension over a wide range of concentrations of these endotoxins when were compared with those that were induced by the standard chemotactic factor, N-formyl-Lmethionyl-L-leucyl-L-phenylalanine (FMLP). It was discovered that all of the endotoxins induced locomotor responses in neutrophils in suspension that were dose- and time-dependent. The optimum concentration for the endotoxins of $S$. dysenteriae, $V$. cholerae, and $K$. pneumoniae was $1 \mathrm{mg} / \mathrm{ml}$ in which 71, 69, and $66 \%$ of the neutrophils were polarized. However, the $S$. typhimurium dose was $2 \mathrm{mg} / \mathrm{ml}$ in which $50 \%$ of the cells responded. Neutrophils that were stimulated with endotoxins also showed increased random locomotion $(\mathbf{p}<0.005)$ through cellulose nitrate filters, but an enhanced adhesion of the cells to glass surfaces $(\mathbf{p}<\mathbf{0 . 0 3})$. These are important functions of these cells to reach and phagocytose damaged cells, as well as invading microorganisms. Interestingly, the endotoxins had a highly-significant inhibitory effect upon the proportions of neutrophils phagocytosing opsonized yeast $(p<0.01)$ with a small number of yeast that were engulfed by the cells $(\mathbf{p}<0.02)$. Further, endotoxin-treated cells showed an enhanced ability to reduce NBT dye $(p<0.03)$. Therefore, we concluded that endotoxins of enteric pathogens are neutrophil chemotactic factors.
\end{abstract}

*To whom correspondence should be addressed.

Tel: 880-2-8625303; Fax: 880-2-8615583

E-mail: laila@udhaka.net
Keywords: Endotoxins, Locomotion, Neutrophil polarization, Phagocytosis

\section{Introduction}

Neutrophils, the most numerous blood leukocytes, are considered to be the body's first line of defense since they combat infection by a series of events. These include adherence to blood vessels that is followed by transmigrating into tissues, random migration and chemotaxis, phagocytosis, and ultimately microbial killing. Commencement of the morphologic events that are the initial steps for the recruitment of neutrophils in response to infectious agents requires the integrity and coordination of a complicated series of cellular functions (Valletta et al., 1989). The ability to survive an infectious challenge may depend on the appropriate modulation of these neutrophil functions.

Lipopolysaccharide (LPS, endotoxin), an important component of the cell wall of gram-negative bacteria, is a potent agonist for priming and stimulating neutrophils, and is responsible for the pathogenecity of these organisms (Luchi and Munford, 1993). Injection of endotoxin into rabbits is known to induce selective dysfunction of peripheral blood neutrophils in response to endogenous chemotactic factors, such as leukotriene $\mathrm{B}_{4}$ and C5a (Hartiala et al., 1985). In recent studies, neutrophils that were isolated from rat lungs after a challenge with endotoxin demonstrated a significant delay in spontaneous apoptosis (Watson et al., 1997).

Interaction of neutrophils with LPS is mediated by the cell surface protein CD14 in the presence of serum factors, such as LPS-binding protein and septin (Shapira et al., 1995), or by cell surface L-selectin. However, this latter binding is independent of serum and $\mathrm{Ca}^{2+}$ (Malhotra et al., 1996). Consequences of these interactions cause cell polarization, as well as F-actin redistribution, without a net gain in the F-actin content (Howard et al., 1990). Reportedly, endotoxin can suppress macrophage phagocytosis by altering the distribution of microfilaments and microtubules; thereby, they act on the 
cytoskeletal network of the cells (Wonderling et al., 1996).

However, previous studies did not examine the effects of endotoxins on neutrophil functions by directly adding these to the cells in suspension. Recently, we studied the LPS effects of $V$. cholerae (Islam et al., 1997) and $S$. dysenteriae (Islam et al., 1998) on different functional aspects of blood neutrophils. In the present study, we investigated and compared the effects of endotoxins from four pathogenic bacteria on the morphological polarization, phagocytosis, adhesion, locomotion, and NBT dye reduction by human neutrophils.

\section{Materials and Methods}

Endotoxins The endotoxin from the $S$. dysenteriae type 1 was obtained by the phenol-water extraction procedure (Westphal and Jann, 1965). Endotoxins of other pathogenic bacteria ( $V$. cholerae Inaba 569B, $S$. typhimurium and $K$. pneumoniae) that were obtained by the same procedure were procured from Sigma.

Isolation of neutrophils Peripheral blood was drawn from normal, healthy human adults. The neutrophils were purified by the standard procedure of dextran sedimentation, followed by centrifugation on Ficoll-Hypaque through which the cells were collected as pellets (Shields and Haston, 1985). These cells were washed with a Hank's balanced salt solution that contained $10 \mathrm{mM}$ morpholinopropane sulfonic acid (HBSS-MOPS).

Polarization assays Neutrophils at $1 \times 10^{6}$ cells $/ \mathrm{ml}$ in HBSSMOPS were taken in several tissue culture plastic tubes. Different concentrations of the endotoxins were added to the cells. N-formylL-methionyl-L-leucyl-L-phenylalanine (FMLP, Sigma) at $10^{-8} \mathrm{M}$ was used as the standard chemotactic factor in these experiments. The cells were incubated at $37^{\circ} \mathrm{C}$, fixed with $2 \%$ glutaraldehyde, washed, then examined under an Olympus $\mathrm{CH}-30$ microscope. The polarized cells were scored as described elsewhere (Shields and Haston, 1985; Islam and Wilkinson, 1988).

Phagocytosis assays Neutrophils at $1 \times 10^{6}$ cells/ml that were pretreated with bacterial endotoxins were placed on microscope slides, left undisturbed to settle on and attach, and then allowed to phagocytose opsonized baker's yeast (preincubated in fresh plasma, then washed) at $37^{\circ} \mathrm{C}$. The neutrophil proportions that were attached to at least three yeasts were counted as phagocytic cells. The number of yeast that was bound to one hundred randomlychosen neutrophils were determined by counting 300 cells (Islam $e t$ al., 1997). Also, the cell proportions that were attached with more than 10 yeast were counted from each preparation as the measure of efficiency of neutrophil phagocytosis.

Adhesion assays Neutrophils $\left(5 \times 10^{5}\right.$ cells/test $)$ in human serum albumin (HSA, Sigma) at $5 \mathrm{mg} / \mathrm{ml}$ were allowed to adhere on glass coverslips in the presence and absence of endotoxins that were dissolved in HSA, as detailed earlier (Islam et al., 1997). After a 30 -min incubation at $37^{\circ} \mathrm{C}$, the nonadherent cells were collected, then counted. The proportions of the neutrophils that remained adherent to the coverslips were determined by back calculations.
Locomotion assays About $8 \times 10^{5}$ neutrophils in HSA were allowed to migrate through each cellulose nitrate filter (pore size: $3 \mu \mathrm{m}$, Millipore Ltd., UK) in response to the uniform $1 \mathrm{mg} / \mathrm{ml}$ concentration of different endotoxins that was dissolved in HSA. At the end of a $90-\min$ incubation at $37^{\circ} \mathrm{C}$, the distance into the filter that was attained by the leading front of the cells was measured in ten fields, as described previously (Islam et al., 1997).

NBT reduction assays Neutrophils at $2 \times 10^{6}$ cells $/ \mathrm{ml}$ that were pretreated with different endotoxins in autologous plasma (50\%) were allowed to reduce NBT dye. The reduced dye was extracted in dioxan, and the color intensity was measured at $520 \mathrm{~nm}$.

Statistical analysis Data analyses were carried out using the Statistical Package for Social Sciences (version 8.0 for Windows, SPSS Inc., Chicago, USA). A comparison of the two groups (treated with or without LPS) was carried out using the student's $t$ test for paired samples / equality of means. The differences were considered significant when $p$ was $<0.05$.

\section{Results}

Dose response for neutrophil polarization in endotoxins The endotoxins of all four of the enteric pathogens that were tested in this study induced dose-dependent polarization in neutrophils (Fig. 1). It was observed that the endotoxin of $K$. pneumoniae at the nanogram concentration was capable of inducing neutrophil polarization. A substantial proportion, about $32 \%$ of the cells, was polarized with $100 \mathrm{ng} / \mathrm{ml}$ of $K$. pneumoniae endotoxin. Others induced polarization at $1 \mu \mathrm{g} /$ $\mathrm{ml}$, the proportions of the polarized neutrophils were about $22 \%$, which increased rather sharply from concentrations beyond $10 \mu \mathrm{g} / \mathrm{ml}$. The maximum proportions of the polarized neutrophils with these endotoxins were about $69 \%$ with $V$. cholerae, $66 \%$ with $K$. pneumoniae, and $71 \%$ with $S$. dysenteriae type 1 at a concentration of $1 \mathrm{mg} / \mathrm{ml}$. The endotoxin of $S$. typhimurium was less effective in inducing neutrophil polarization (Fig. 2). This endotoxin caused some $50 \%$ of the cells to become polarized at $2 \mathrm{mg} / \mathrm{ml}$. However, the proportions of polarized neutrophils decreased as the concentrations of all of the endotoxins increased. It was found that about $10-15 \%$ of the cells showed polarized morphology in the medium without endotoxin (points on ordinate, Fig. 2).

Time course of neutrophil polarization in endotoxins The polarization time course showed that about $42 \%$ of the neutrophils became polarized within $5 \mathrm{~min}$ of exposure to the endotoxin of K. pneumoniae, 52\% with V. cholerae, and $59 \%$ with $S$. dysenteriae 1 (Fig. 3). The endotoxin of $S$. typhimurium was found to be less effective in inducing neutrophil polarization, even after $15 \mathrm{~min}$, with only $20-25 \%$ of the cells responding. However, the optimum time for each of these endotoxins towards neutrophil polarization was $30 \mathrm{~min}$ at $37^{\circ} \mathrm{C}$. Further incubation (up to 90 to $120 \mathrm{~min}$ ) decreased the proportions of the polarized cells with all of the 

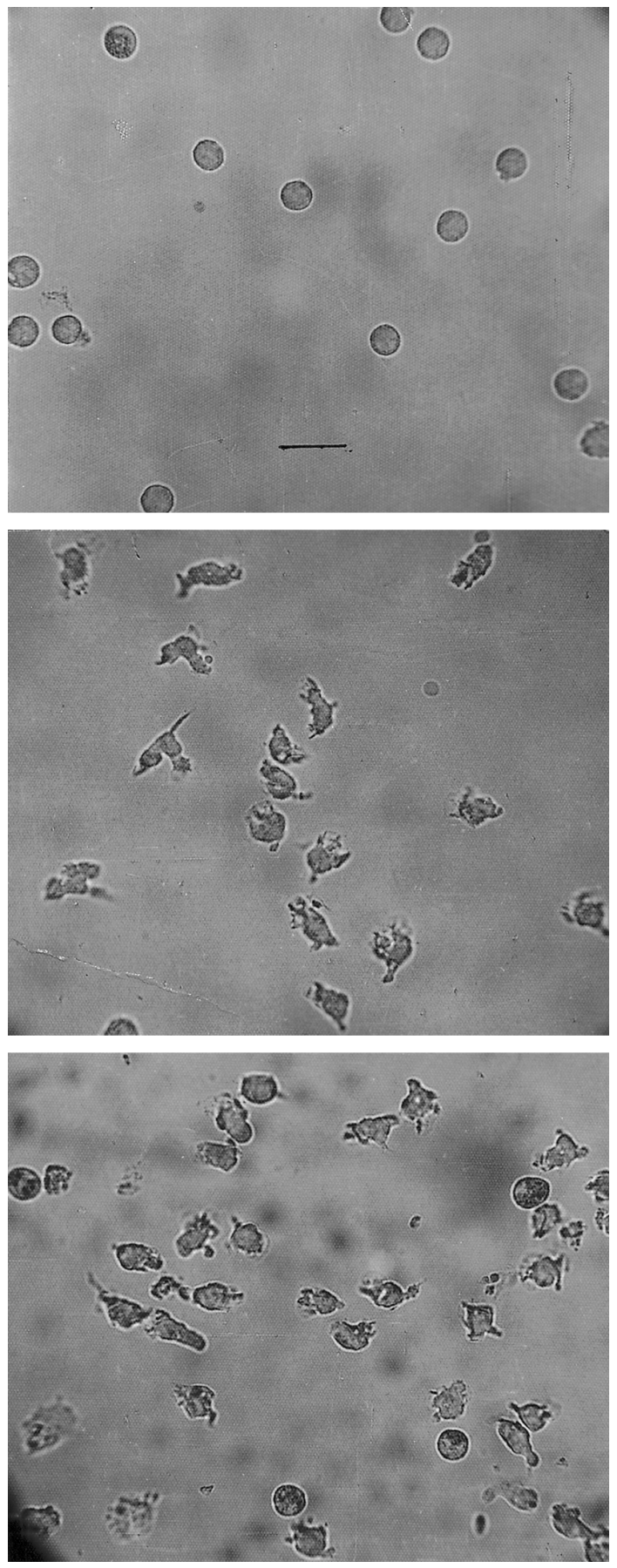

Fig. 1. Photomicrographs of human neutrophils fixed in suspension after incubation for $30 \mathrm{~min}$ at $37^{\circ} \mathrm{C}$ in HBSS-MOPS (top), $10^{-8} \mathrm{M}$ FMLP (middle), and one milligram per ml LPS of $K$. pneumoniae (bottom). All of the photographs are of same magnification, bar $=20 \mu \mathrm{m}$.

endotoxins. It appeared from the time course curves that the endotoxins of $S$. dysenteriae type 1 and $V$. cholerae Inaba 569B showed much higher as well as similar polarization patterns. However, $K$. pneumoniae's response was intermediate. The response of $S$. typhimurium was minimum

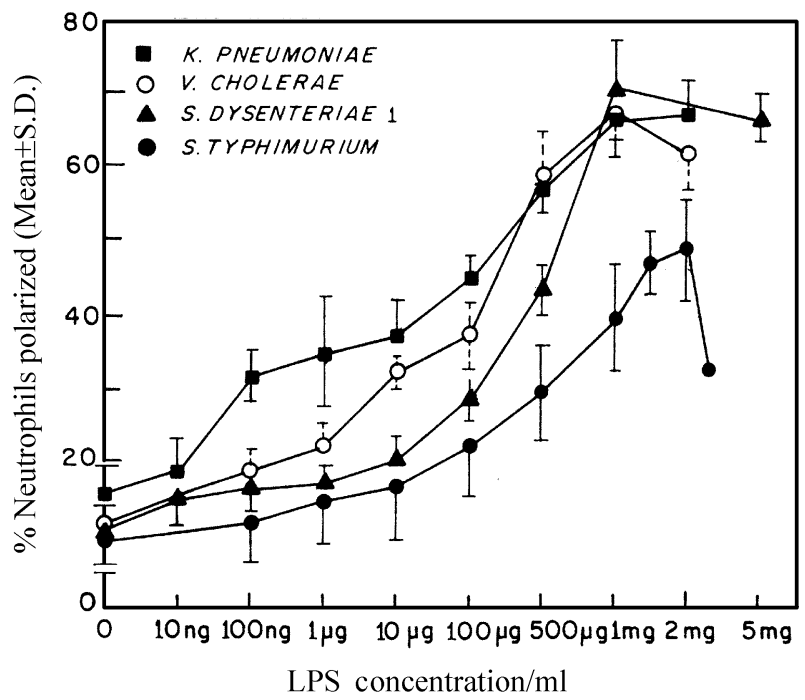

Fig. 2. Dose-response curves for neutrophil polarization in LPS from four pathogenic bacteria. The peak response was observed at $1 \mathrm{mg} / \mathrm{ml}$ LPS when about $66 \%$ of the cells were polarized with the LPS of $K$. pneumoniae ( $\mathbf{\square}), 69 \%$ with $V$. cholerae Inaba 596B ( $\bigcirc)$, and $71 \%$ with $S$. dysenteriae type 1 ( $\Delta$ ), at $2 \mathrm{mg} / \mathrm{ml}$ of the LPS of $S$. typhimurium (O) when approximately $50 \%$ of the cells became polarized.

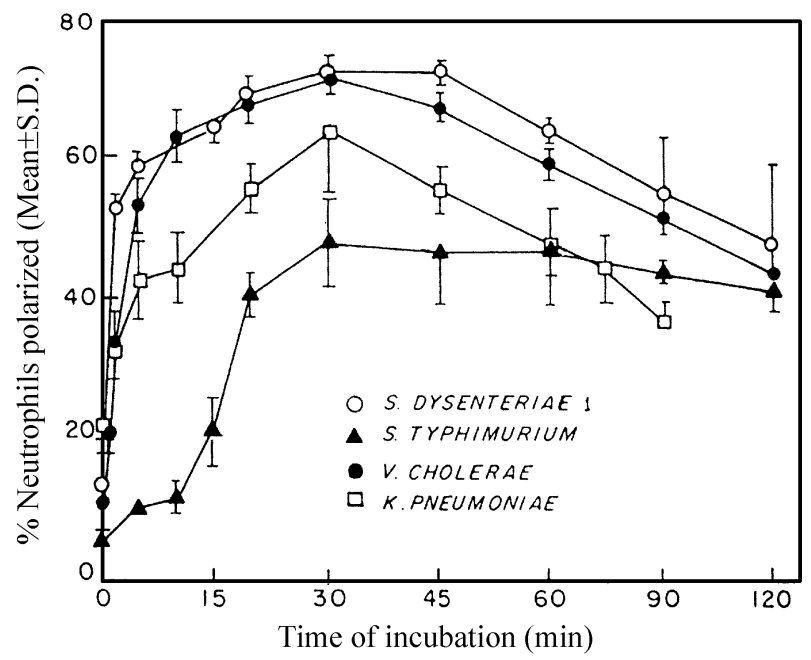

Fig. 3. Time course of neutrophil polarization in endotoxins. The maximum proportion of the polarized cells was obtained after a 30-min incubation with each of these endotoxins.

in stimulating neutrophil polarization.

Effects of endotoxins on neutrophil phagocytosis The proportions of neutrophils that were pretreated with different endotoxins phagocytosing opsonized yeast varied from about $67-90 \%$, while the corresponding values for control cells were between $83-97 \%$ (Fig. 4). The average percentages of the neutrophils phagocytosing opsonized yeast, while pretreated with the endotoxin of the $S$. dysenteriae type 1 was about 


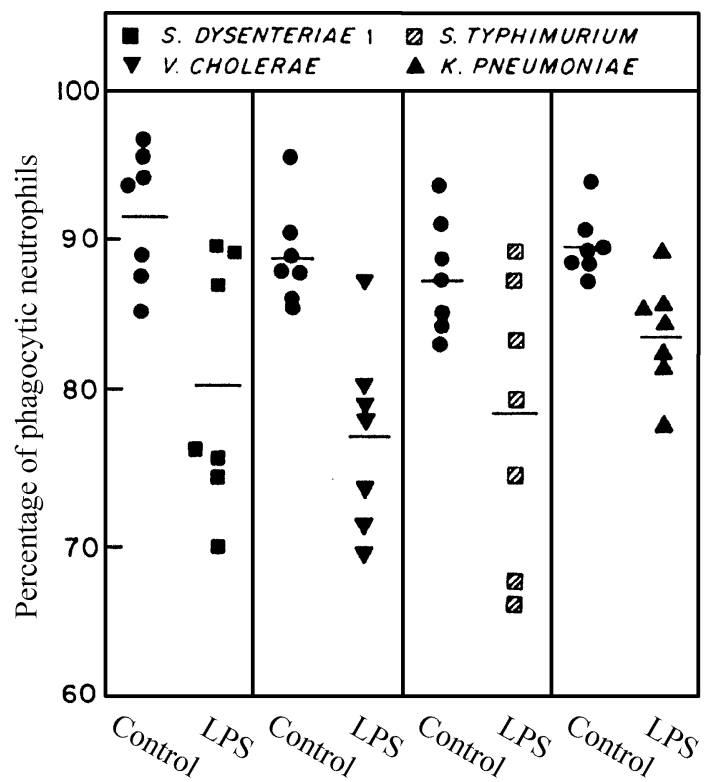

Fig. 4. The proportions of neutrophils pretreated with different LPS phagocytosing opsonized yeast. Each symbol represents a single experiment using neutrophils from a healthy subject. The horizontal bars represent the mean values.

$80 \%$, V. cholerae was $77 \%$, S. typhimurium was $78 \%$, and $K$. pneumoniae was $84 \%$. The mean values with the control cells were between $88-92 \%$ in these four sets of experiments. It was found that all of the endotoxins significantly suppressed the proportions of the neutrophils phagocytosing opsonized yeast $(\mathrm{p}<0.02)$. Endotoxin-treated neutrophils were also found to bind to fewer yeast cells $(\mathrm{p}<0.02$, Table 1$)$. Further, the efficiency of phagocytosis, as measured by the ability of the
Table 1. Effects of endotoxins on the number of yeast and efficiency of phagocytosis by the neutrophils

\begin{tabular}{lcc}
\hline \multirow{2}{*}{$\begin{array}{c}\text { Neutrophil } \\
\text { pretreatment with: }\end{array}$} & $\begin{array}{c}\text { No. of yeast } \\
\text { phagocytosed per } \\
\text { 100 neutrophils }\end{array}$ & $\begin{array}{c}\text { \% Neutrophils } \\
\text { phagocytosing } \\
\text { more than } 10 \\
\text { yeasts }\end{array}$ \\
\cline { 2 - 3 } & $\begin{array}{c}\text { Mean } \pm \text { S.D. } \\
\mathrm{n}=10\end{array}$ & $\begin{array}{c}\text { Mean } \pm \text { S.D. } \\
\mathrm{n}=10\end{array}$ \\
\hline Medium alone & $601.8 \pm 29.0$ & $29.3 \pm 7.4$ \\
LPS of V. cholerae & $464.1 \pm 31.2$ & $21.3 \pm 11.0$ \\
& $\mathrm{p}<0.001$ & $\mathrm{p}<0.05$ \\
Medium alone & $631.0 \pm 69.6$ & $11.3 \pm 7.0$ \\
LPS of $S$. dysenteriae 1 & $488.7 \pm 115.3$ & $7.7 \pm 4.3$ \\
& $\mathrm{p}<0.02$ & $\mathrm{p}>0.05$ \\
Medium alone & $571.6 \pm 56.7$ & $10.0 \pm 4.4$ \\
LPS of $K$. pneumoniae & $499.0 \pm 20.9$ & $5.8 \pm 2.7$ \\
& $\mathrm{p}<0.01$ & $\mathrm{p}<0.05$ \\
Medium alone & $532.7 \pm 86.8$ & $11.6 \pm 5.7$ \\
LPS of $S$. typhimurium & $405.0 \pm 56.5$ & $6.9 \pm 5.2$ \\
& $\mathrm{p}<0.001$ & $\mathrm{p}<0.05$ \\
\hline
\end{tabular}

cells to attach to more than 10 yeast, was suppressed by all of the endotoxins. These results show that endotoxins of enteric pathogens have inhibitory effects on the phagocytic function of the neutrophils.

Effects of endotoxins on neutrophil adhesion, locomotion, and NBT dye reduction The endotoxins were tested for their probable effects on these functions of neutrophils. The results are shown in Table 2. It was observed that all of the

Table 2. Effects of endotoxins on adhesion, locomotion, and NBT dye reduction by the neutrophils

\begin{tabular}{|c|c|c|c|}
\hline \multirow{2}{*}{ Neutrophil pretreatment with: } & $\begin{array}{l}\text { Adhesion (percentage of } \\
\text { adherent cells) }\end{array}$ & $\begin{array}{l}\text { Locomotion (leading } \\
\text { front value in } \mu \mathrm{m} \text { ) }\end{array}$ & $\begin{array}{l}\text { NBT reduction (reduced NBT } \\
\text { dye in dioxan, O.D at } 520 \mathrm{~nm} \text { ) }\end{array}$ \\
\hline & Mean \pm S.D. $n=10$ & Mean \pm S.D. $n=10$ & Mean \pm S.D. $n=10$ \\
\hline \multirow{3}{*}{$\begin{array}{l}\text { Medium alone } \\
\text { LPS of } V \text {. cholerae }\end{array}$} & $64.0 \pm 3.0$ & $63.0 \pm 5.7$ & $0.075 \pm 0.022$ \\
\hline & $71.7 \pm 2.4$ & $108.0 \pm 8.8$ & $0.155 \pm 0.035$ \\
\hline & $* *$ & $* * *$ & $*$ \\
\hline \multirow{3}{*}{$\begin{array}{l}\text { Medium alone } \\
\text { LPS of } S . \text { dysenteriae } 1\end{array}$} & $65.0 \pm 13.8$ & $60.0 \pm 5.7$ & $0.053 \pm 0.006$ \\
\hline & $75.3 \pm 16.6$ & $75.2 \pm 9.3$ & $0.152 \pm 0.004$ \\
\hline & $*$ & $* * *$ & $* * *$ \\
\hline \multirow{3}{*}{$\begin{array}{l}\text { Medium alone } \\
\text { LPS of } K . \text { pneumoniae }\end{array}$} & $56.1 \pm 3.3$ & $55.6 \pm 8.0$ & $0.078 \pm 0.008$ \\
\hline & $78.4 \pm 7.3$ & $76.8 \pm 14.2$ & $0.173 \pm 0.041$ \\
\hline & $* *$ & $* *$ & $*$ \\
\hline \multirow{3}{*}{$\begin{array}{l}\text { Medium alone } \\
\text { LPS of } S . \text { typhimurium }\end{array}$} & $51.8 \pm 2.5$ & not done & not done \\
\hline & $72.7 \pm 5.7$ & & \\
\hline & $* *$ & & \\
\hline
\end{tabular}

$* * * \mathrm{p}<0.001 ; * * \mathrm{p}<0.005 ; * \mathrm{p}<0.03$ 
endotoxins significantly enhanced neutrophil adhesion to glass surfaces $(\mathrm{p}<0.03)$, and chemokinetically stimulated the cells to migrate into filters in locomotion assays $(p<0.005)$. However, the effects of these endotoxins on the proportions of the neutrophils that adhere to glass surfaces were very close, about $72-78 \%$, although their effects on cell locomotion through filters were different. The efficacy of $V$. cholerae endotoxin was found to be much higher than those of other enteric pathogens in stimulating the random locomotion of the cells. In the presence of fresh plasma, the endotoxins acted as a phagocytic stimulus, and the enhanced oxidative metabolism of the cells resulted in an increased NADPH oxidation. This is because the NBT dye reduction ability of the neutrophils was significantly enhanced by these endotoxins $(\mathrm{p}<0.03)$.

\section{Discussion}

The endotoxins of four pathogenic bacteria were studied for their effects on the functions of neutrophils from healthy adults. To demonstrate their probable effects on neutrophil morphology, we directly added endotoxins to the cells in suspension, and estimated the proportions of neutrophils that were polarized. It was discovered that endotoxin had the ability to induce shape change or morphological polarization in neutrophils that would indicate an early event to be followed by their subsequent chemotactic response. Previous workers used polarization assays to study the responses of neutrophils (Shields and Haston, 1985) and monocytes (Islam and Wilkinson, 1988) to chemotactic factors. We report that all of the endotoxins that were tested in this study acted as chemotactic factors; each one has the ability to change the shape or stimulate the neutrophils to acquire locomotor morphology in a dose- and time-dependent manner. However, the responses varied with the endotoxin of one pathogen to another.

The identity of the receptor that is responsible for endotoxin signaling and leukocyte activation is unknown. Recently, it was discovered that L-selectin is a neutrophil surface receptor for endotoxin and lipotechoic acid, and the interaction of endotoxin with the cell surface L-selectin results in superoxide production. This indicates that L-selectin can mediate both binding and activation of human neutrophils (Malhotra et al., 1996). Endotoxin modulates FMLP-induced actin polymerization in neutrophils since it is associated with an increase in the number of FMLP receptors that are expressed on the cell surface (Howard et al., 1990). However, we believe that neutrophil polarization may be a multi-step process that is inducible by compounds that trigger different biochemical events, as suggested earlier (Iannone and Wolberg, 1989).

Pretreatment of neutrophils with each of these endotoxins showed significantly-suppressed phagocytic activity towards opsonized baker's yeast. In a phagocytic activity assessment, the scoring criterion was a modification of visual method that were described previously for the phagocytosis of Candida albicans by neutrophils (Allan and Wilkinson, 1978) and monocytes (Islam and Wilkinson, 1989) in which we did not distinguish between the engulfed yeast from the membranebound yeast. Our observations suggest that acquiring polarized morphology that is due to pretreatment with endotoxin was not essential for the neutrophils to exhibit phagocytic activity. This is because the control cells with spherical morphologies were found to be phagocytic. Also, the inhibitory effects of different endotoxins on neutrophil phagocytosis were similar, although their effects on morphological polarization of the cells were different. This suggests that the expression of cell polarization and phagocytic activity require different signals.

Our observations further suggest that endotoxin may directly interfere with $\mathrm{C} 3 \mathrm{~b}$ - and/or Fc-receptor-mediated phagocytic activity of the cells, thereby suppressing the neutrophil function. Although reports are not yet available on the effects of endotoxin on these cell surface receptors, it was discovered that the LPS receptor, CD14, is involved in the phagocytosis of gram-negative bacteria by human monocytes (Grunwald et al., 1996). However, IL-1 $\beta$ and TNF $\alpha$ are known to up-regulate Fcr receptor-mediated phagocytosis by human neutrophils. The mechanisms though are still unknown (Garner et. al., 1996).

Human neutrophils that are primed by endotoxin show the up-regulation of beta-2 integrins and the down-regulation of L-selectin. This suggests that adhesion molecules serve a modulatory role in the expression of neutrophil-programmed cell death (Watson et al., 1997). Neutrophils exhibit a dramatic enhancement of integrin-mediated cell adhesion in response to endotoxin that requires CD14 on the cells and plasma proteins in solution (Park and Wright, 1996). In this study, we used purified human serum albumin instead of fresh plasma in the adhesion and locomotion assays. We found that both of these neutrophil functions are highly enhanced by endotoxins.

We used a NBT dye reduction assay to study the metabolic function of the cells since the respiratory burst-dependent NBT reduction in phagocytes occur by a chemical reaction between the dye and the $\mathrm{O}^{-2}$ that is generated during the burst, which in turn is related to hexose monophosphate shunt and NADPH production (Ardati et al., 1997). Therefore, the dye may be used to measure the ability of the neutrophils to kill microbes because of the close association between microbicidal function and dye reduction. Neutrophils showed a modest increase in NBT reduction following in vitro endotoxin exposure in the presence of plasma, presumably due to the generation of C5a, a known activator of oxygen metabolism. This observation confirms the findings of previous workers (Proctor, 1979; Wilson, 1985).

In summary, all of the endotoxins that were tested in this study showed similar effects on neutrophils. Endotoxins of enteric pathogens stimulate human neutrophils to acquire polarized morphology, thereby acting as neutrophilchemotactic factors. Besides the inhibitory effect of the endotoxins on neutrophil-phagocytosis of baker's yeast, we 
also found other functions, for example, adhesion, locomotion, and NBT dye reduction by these cells were enhanced by endotoxins. However, endotoxins may suppress phagocytosis via its effects on the cytoskeletal network of the cells (Wonderling et al., 1996). Our results indicate that endotoxin-stimulated neutrophils appear to have an enhanced ability to sense and respond to changes in the extracellular environment and may, therefore, represent an important avenue in augmenting the host defense.

\section{References}

Allan, R. B. and Wilkinson, P. C. (1978) A visual analysis of chemotactic and chemokinetic locomotion of human neutrophil leukocytes. Use of a new chemotaxis assay with Candida albicans as gradient source. Exp. Cell Res. 111, 191-203.

Ardati, K. O., Bajakian, K. M. and Tabbara, K. S. (1997) Effect of glucose-6-phosphate dehydrogenase deficiency on neutrophil function. Acta Haematol. 97, 211-215.

Garner, C. V., D'Amico, R. and Simms, H. H. (1996) Cytokinemediated human polymorphonuclear neutrophil phagocytosis: evidence of differential sensitivities to manipulation of intracellular mechanisms. J. Surg. Res. 60, 84-90.

Grunwald, U., Fan, X., Jack, R. S., Workalemadu, G., Kallies, A., Stelter, F. and Schutt, C. (1996) Monocytes can phagocytose Gram-negative bacteria by a CD-14 dependent mechanism. $J$. Immunol. 157, 4119-4125.

Hartiala, K. T, Langlois, L., Goldstein, I. M. and Rosenbaum, J. T. (1985) Endotoxin-induced selective dysfunction of rabbit polymorphonuclear leukocytes in response to endogenous chemotactic factors. Intect. Immun. 50, 527-533.

Howard, T. H., Wang, D. and Berkow, R. L. (1990) Lipopolysaccharide modulates chemotactic peptide induced actin polymerization in neutrophils. J. Leukoc. Biol. 47, 13-24.

Iannone, M. A. and Wolberg, G. (1989) Effects of adenosine on neutrophil polarization induced by $\mathrm{N}$-formyl-methionyl-leucylphenylalanine, sodium propionate and colchicines. Agents Actions 27, 403-406.

Islam, L. N., Ahmed. K. M. and Shammy, S. (1997) Modulation of human neutrophil function by Vibrio cholerae lipopolysaccharide. Banhgladesh J. Biochem. 3, 75-86.

Islam, L. N., Chowdhury, U. K., Roy, A. K., Hossain, M. K., Shammy, S. and Islam, M. S. (1998) Human neutrophil responses to LPS, OMP and toxin of Shigella dysenteriae type 1 and comparison with responses to FMLP. Dhaka Univ. J. Biol. Sci. 7, 99-112.
Islam, L. N. and Wilkinson, P. C. (1988) Chemotactic factorinduced polarization, receptor redistribution, and locomotion of human blood monocytes. Immunology 64, 501-507.

Islam, L. N. and Wilkinson, P. C. (1989) Evaluation of methods for isolating human peripheral blood monocytes. Studies on chemotactic locomotion and other functional characteristics. $J$. Immunol. Meth. 121, 75-84.

Luchi, M. and Munford, R. S. (1993) Binding, internalization and deacylation of bacterial lipopolysaccharide by human neutrophils J. Immunol. 151, 959-969.

Malhotra, R., Priest, R. and Bird, M. I. (1996) Role for L-selectin in lipopolysaccharide-induced activation of neutrophils. $J$. Biochem. 320, 589-593.

Park, C. T. and Wright, S. D. (1996) Plasma lipopolysaccharide binding protein is found associated with particle containing apolipoprotein A-I, phospholipid and factor-H related proteins. J. Biol. Chem. 271, 18054-18060.

Proctor, R. A. (1979) Endotoxin in vitro interactions with human neutrophils: depression of chemiluminescence, oxygen consumption, super oxide production, and killing. Infect. Immun. 25, 912-921.

Shapira, L., Champagne, C., Gordon, B., Amar, S. and Van-Dyke, T. E. (1995) Lipopolysaccharide priming of superoxide release by human neutrophils: role of membrane CD14 and serum LPS binding protein. Inflammation 19, 289-295.

Shields, J. M. and Haston, W. S. (1985) Behaviour of neutrophil leukocytes in uniform concentration of chemotactic factors: contraction waves, cell polarity and persistence. J Cell Sci.74, 75-93.

Valletta, E. A., Cazzola, G. A. and Cipolli, M. (1989) Neutrophil chemotaxis.I. Physiology aspects and study methods. Pediatr. Med. Chir. 11, 617-622.

Watson, R. W., Rotstein, O. D., Nathens. A. B., Parodo, J. and Marshall, J. C. (1997) Neutrophil apoptosis is modulated by endothelial transmigration and adhesion molecule engagement. J. Immunol. 158, 945-953.

Westphal, O. and Jann, K. (1965) Bacterial lipopolysaccharides: Extraction with phenol water and further application of the procedure; in Methods in Carbohydrate Chemistry (Whister, R. L. and Wolfrom, M. L., eds.), Vol. 5, pp. 88, Academic Press Inc., New York.

Wilson, M. E. (1985) Effects of bacterial endotoxins on neutrophil function. Rev. Infect. Dis. 7, 404-418.

Wonderling, R. S., Ghaffar, A. and Mayer, E. P. (1996) Lipopolysaccharide-induced suppression of phagocytosis: effects on phagocytic machinery. Immunopharmacol. Immunotoxicol. 18, 267-289. 